\title{
Development of a self-administered questionnaire to screen patients for cervical myelopathy
}

\author{
Hiroshi Kobayashi", Shin-ichi Kikuchi, Koji Otani, Miho Sekiguchi, Yasufumi Sekiguchi, Shin-ichi Konno
}

\begin{abstract}
Background: In primary care, it is often difficult to diagnose cervical myelopathy. However, a delay in treatment could cause irreversible aftereffects. With a brief and effective self-administered questionnaire for cervical myelopathy, cervical myelopathy may be screened more easily and oversight may be avoided. As there is presently no screening tool for cervical myelopathy, the aim of this study was to develop a self-administered questionnaire for the screening of cervical myelopathy.

Methods: A case-control study was performed with the following two groups at our university hospital from February 2006 to September 2008. Sixty-two patients (48 men, 14 women) with cervical myelopathy who underwent operative treatment were included in the myelopathy group. In the control group, 49 patients (20 men, 29 women) with symptoms that could be distinguished from those of cervical myelopathy, such as numbness, pain in the upper extremities, and manual clumsiness, were included. The underlying conditions were diagnosed as carpal tunnel syndrome, cubital tunnel syndrome, thoracic outlet syndrome, tarsal tunnel syndrome, diabetes mellitus neuropathy, cervical radiculopathy, and neuralgic amyotrophy. Twenty items for a questionnaire in this study were chosen from the Japanese Orthopaedic Association Cervical Myelopathy Evaluation Questionnaire, which is a new self-administered questionnaire, as an outcome measure for patients with cervical myelopathy. Data were analyzed by univariate analysis using the chi-square test and by multiple logistic regression analysis. According to the resulting odds ratio, $\beta$-coefficients, and $p$ value, items were chosen and assigned a score.
\end{abstract}

Results: Eight items were chosen by univariate and multiple logistic regression analyses and assigned a score. The Hosmer-Lemeshow statistic showed $p=0.805$. The area under the receiver operation characteristic curve was 0.86 . The developed questionnaire had a sensitivity of $93.5 \%$ and a specificity of $67.3 \%$.

Conclusions: We successfully developed a simple self-administered questionnaire to screen for cervical myelopathy.

\section{Background}

Cervical myelopathy is caused by mechanical and dynamic compression of the spinal cord and developmental spinal canal stenosis [1]. Patients with cervical myelopathy have various symptoms, such as numbness, pain, hypoesthesia and weakness of the extremities, pain and stiffness of the neck, manual clumsiness, walking disturbance, and urinary disturbance [2-5]. Numbness of the upper extremities is one of the chief symptoms in cervical myelopathy and patients with cervical myelopathy who have this numbness frequently consult a general outpatient clinic or a primary care practitioner. Upper

\footnotetext{
* Correspondence: hkhk0105@yahoo.co.jp

Department of Orthopaedic Surgery, Fukushima Medical University School of Medicine, Fukushima, Japan
}

extremity numbness may also be caused by entrapment neuropathy, such as carpal and cubital tunnel syndromes. Therefore, diagnosis of cervical myelopathy in such patients is sometimes difficult and costly in primary care. To make an accurate diagnosis, much data must be examined, such as the case history, physical examination including a neurological examination, and imaging tests. Furthermore, misdiagnosis and delayed treatment may result in irreversible consequences, such as paralysis, urinary disturbance, and walking disturbance. Therefore, accurate diagnosis and treatment by a specialist are needed for a good outcome. If there were a brief, selfadministered questionnaire for cervical myelopathy screening, patients could answer it easily while waiting for a primary care or outpatient clinic consultation. 
However, there is presently no scientifically established questionnaire to screen for cervical myelopathy. The aim of this study was to develop a self-administered questionnaire to screen for cervical myelopathy.

\section{Methods}

\section{Ethical considerations}

The present study was approved by the institutional review board of Fukushima Medical University and was conducted in compliance with ethical standards. All participants gave their written informed consent.

\section{Objective}

One hundred eleven patients were enrolled in this casecontrol study (Table 1$)$. In the myelopathy group, 62 patients (48 men, 14 women) with a diagnosis of cervical myelopathy who underwent surgery at Fukushima Medical University Hospital from February 2006 to September 2008 were included. Cervical myelopathy was secondary to a herniated disc in 5 patients, spondylosis in 32 patients, ossification of the posterior longitudinal ligament in 22 patients, and a combination of these in three patients. To develop a questionnaire to screen for cervical myelopathy, the control group comprised patients with upper extremity symptoms not caused by cervical myelopathy. Patients with dementia, a history of cervical operations, rheumatoid arthritis, infectious spondylitis, cervical myotrophy, tumor, spinal injury, cerebral infarction, and trauma were excluded.

Table 1 Demographic data of the Myelopathy and Control groups

\begin{tabular}{|c|c|c|c|c|}
\hline & $\begin{array}{l}\text { Control group } \\
(n=49)\end{array}$ & & $\begin{array}{l}\text { Myelopathy } \\
(\mathrm{n}=62)\end{array}$ & group \\
\hline $\begin{array}{l}\text { Mean age } \\
\text { (y (SD) }\end{array}$ & $62.1(13.3)$ & & $62.3(13.8)$ & \\
\hline Male (\%) & 20 (38.8) & & $48(77.4)$ & \\
\hline Female (\%) & $29(61.2)$ & & 14 (22.6) & \\
\hline \multirow[t]{8}{*}{ Diagnosis (\%) } & CTS & $34(69.4)$ & CSM & 32 (51.6) \\
\hline & CuTS & 9 (18.4) & $\mathrm{CDH}$ & $5(8.1)$ \\
\hline & CTS + CUTS & $1(2.0)$ & OPLL & $22(35.5)$ \\
\hline & CTS + DN & $1(2.0)$ & combination & $3(4.8)$ \\
\hline & TTS + DN & $1(2.0)$ & & \\
\hline & TOS & $1(2.0)$ & & \\
\hline & $\begin{array}{l}\text { Cervical } \\
\text { radiculopathy }\end{array}$ & $1(2.0)$ & & \\
\hline & $\begin{array}{l}\text { Neuralgic } \\
\text { amyotrophy }\end{array}$ & $1(2.0)$ & & \\
\hline
\end{tabular}

CTS: Carpal Tunnel Syndrome

CuTS: Cubital Tunnel Syndrome

DN: Diabetic Neuropathy

TTS: Tarsal Tunnel Syndrome

TOS: Thoracic Outlet Syndrome

CSM: Cervical Spondylotic Myelopathy

$\mathrm{CDH}$ : Cervical Disc Herniation

OPLL: Ossification of Posterior Longitudinal Ligament

\section{Questionnaire}

There were 20 candidate items for the questionnaire (Table 2), all taken from the Japanese Orthopaedic Association Cervical Myelopathy Evaluation Questionnaire (JOACMEQ), a new self-administered questionnaire used as an outcome measure for patients with cervical myelopathy [6-10]. JOACMEQ is a questionnaire produced by identifying items regarded by specialists as important for the evaluation of cervical myelopathy and performing statistical selection. Its validity and reliability have already been demonstrated [6-9]. JOACMEQ consists of questions about the functional capacity of the cervical spine, physical function of the upper and lower extremities, and bladder function, which might be disturbed by cervical myelopathy, and items for quality of life (QOL). Because QOL items might be useless for screening, the QOL items were not included. To make the questionnaire easy for respondents to answer, the questions were changed to be answered "yes" or "no". Respondents were asked to consider their physical condition in the preceding week. If a respondent's condition had changed depending on the day or the time, the respondent was asked to identify

\section{Table 2 Candidates from the JOACMEQ questionnaire}

\begin{tabular}{|c|c|}
\hline$\overline{\mathrm{Q} 1-1}$ & $\begin{array}{l}\text { While in the sitting position, can you look up at the ceiling } \\
\text { by tilting your head upward? }\end{array}$ \\
\hline Q1-2 & $\begin{array}{l}\text { Can you drink a glass of water without stopping despite } \\
\text { the neck symptoms? }\end{array}$ \\
\hline Q1-3 & $\begin{array}{l}\text { While in the sitting position, can you turn your head } \\
\text { toward the person who is seated to the side but behind } \\
\text { you and speak to that person while looking at his/her } \\
\text { face? }\end{array}$ \\
\hline Q1-4 & Can you look at your feet when you go down the stairs? \\
\hline Q2-1 & $\begin{array}{l}\text { Can you fasten the front buttons of your blouse or shirt } \\
\text { with both hands? }\end{array}$ \\
\hline Q2-2 & $\begin{array}{l}\text { Can you eat a meal with your dominant hand using a } \\
\text { spoon or a fork? }\end{array}$ \\
\hline Q2-3 & Can you raise your arm? (Answer for the weaker side.) \\
\hline Q3-1 & Can you walk on a flat surface? \\
\hline Q3-2 & $\begin{array}{l}\text { Can you stand on either leg without holding onto } \\
\text { something? (or the need to support yourself) }\end{array}$ \\
\hline Q3-3 & $\begin{array}{l}\text { Do you have difficulty climbing the stairs to one floor } \\
\text { above? }\end{array}$ \\
\hline Q3-4 & $\begin{array}{l}\text { Do you have difficulty bending forward, keeling, and } \\
\text { stopping? }\end{array}$ \\
\hline Q3-5 & Do you have difficulty walking for 15 minutes? \\
\hline Q4-1 & Do you have urinary incontinence? \\
\hline Q4-2 & Do you go to the bathroom at night? \\
\hline Q4-3 & $\begin{array}{l}\text { Do you have a feeling of residual urine in your bladder } \\
\text { after voiding? }\end{array}$ \\
\hline Q4-4 & $\begin{array}{l}\text { Can you initiate (start) your urine stream immediately } \\
\text { when you want to void? }\end{array}$ \\
\hline Q5 & Do you have neck pain, shoulder pain, and neck stiffness? \\
\hline Q6 & Do you have chest tightness? \\
\hline Q7 & Do you have pain or numbness in the upper extremity? \\
\hline Q8 & Do you have pain or numbness from chest to forefoot? \\
\hline
\end{tabular}


the worst condition by circling the item number of "your worst condition". Patients in the myelopathy group answered the questionnaire a day before surgery. In the control group, outpatients satisfying the criteria answered the questionnaire prospectively in the outpatient clinic. The answers to these items were compared between the two groups.

\section{Statistical analyses}

First, the chi-square test was used for univariate analysis. Odds ratios (ORs), 95\% confidence intervals $(95 \% \mathrm{CI})$, and $p$ values were calculated. Items with ORs $\geq 2$ and $p$ values $<0.05$ were included in the multiple logistic regression analysis. Next, $\beta$-coefficients, adjusted ORs, $95 \% \mathrm{CI}$, and $\mathrm{p}$ values were calculated. Items with ORs $<2$ were removed.

Using a regression coefficient-based scoring system, a score-based questionnaire to screen patients with cervical myelopathy was developed based on the multiple logistic regression equations. The calibration was evaluated using the Hosmer-Lemeshow chi-square statistic ( $p>0.05$ for all models); $\mathrm{p} \geq 0.05$ supports the goodness of fit.

To generate a simple integer-based point score for each predictor variable, scores were assigned by dividing the $\beta$-coefficient by two-fifths of the sum of the two smallest coefficients in the model and rounding up to the nearest

Table 3 Univariate analysis for factors from the questionnaire

\begin{tabular}{|c|c|c|c|c|c|}
\hline \multirow[b]{2}{*}{ Item } & \multicolumn{2}{|c|}{ Positive rate } & \multirow[b]{2}{*}{ OR } & \multirow[b]{2}{*}{$95 \% \mathrm{Cl}$} & \multirow[b]{2}{*}{$p$ value } \\
\hline & Control & Myelopathy & & & \\
\hline Q1-1 & 2.08 & 11.29 & 5.98 & $0.71-50.39$ & 0.135 \\
\hline Q1-2 & 18.75 & 22.58 & 1.26 & $0.50-3.23$ & 0.646 \\
\hline Q1-3 & 14.58 & 36.07 & 3.30 & $1.27-8.60$ & $0.016 *$ \\
\hline Q1-4 & 8.33 & 16.67 & 2.20 & $0.64-7.51$ & 0.255 \\
\hline Q2-1 & 14.58 & 32.26 & 2.79 & $1.07-7.30$ & $0.044 *$ \\
\hline Q2-2 & 6.25 & 11.29 & 1.91 & $0.47-7.81$ & 0.509 \\
\hline Q2-3 & 14.58 & 4.84 & 0.30 & $0.073-1.22$ & 0.10 \\
\hline Q3-1 & 2.08 & 9.68 & 5.04 & $0.59-43.3$ & 0.108 \\
\hline Q3-2 & 12.50 & 44.83 & 5.69 & $2.09-19.46$ & $<0.001 *$ \\
\hline Q3-3 & 17.02 & 80.65 & 20.31 & $7.57-54.54$ & $<0.001 *$ \\
\hline Q3-4 & 28.26 & 74.19 & 7.30 & $3.10-17.21$ & $<0.001 *$ \\
\hline Q3-5 & 15.22 & 74.19 & 16.02 & $5.98-42.91$ & $<0.001 *$ \\
\hline Q4-1 & 10.64 & 38.71 & 5.31 & $18.40-15.29$ & $0.001 *$ \\
\hline Q4-2 & 61.70 & 73.77 & 1.75 & $0.77-3.96$ & 0.213 \\
\hline Q4-3 & 23.91 & 55.74 & 4.01 & $1.72-9.33$ & $0.001 *$ \\
\hline Q4-4 & 10.64 & 54.84 & 10.20 & $3.56-29.25$ & $<0.001 *$ \\
\hline Q5 & 51.02 & 89.83 & 8.48 & $3.08-23.36$ & $<0.001 *$ \\
\hline Q6 & 2.08 & 32.76 & 22.90 & $2.93-178.79$ & $<0.001 *$ \\
\hline Q7 & 66.67 & 98.31 & 29.00 & $3.68-228.87$ & $<0.001 *$ \\
\hline Q8 & 20.83 & 79.66 & 14.88 & $5.80-38.172$ & $<0.001 *$ \\
\hline
\end{tabular}

${ }^{*} p<0.05$ and $\mathrm{OR} \geq 2$, OR: odds ratio, Cl: confidence interval
Table 4 Multivariate analysis

\begin{tabular}{lllll}
\hline Item & $\boldsymbol{\beta}$-coefficient & Adjusted OR & $\mathbf{9 5 \%} \mathbf{C l}$ & $\boldsymbol{p}$ value \\
\hline Q1-3 & -1.79 & 0.17 & $0.009-3.11$ & 0.23 \\
Q2-1 & 0.482 & 1.619 & $0.13-19.78$ & 0.71 \\
Q3-2 & -0.79 & 0.45 & $0.025-8.14$ & 0.59 \\
Q3-3 & 2.96 & 19.24 & $0.88-420.71$ & $0.06 *$ \\
Q3-4 & -1.04 & 0.36 & $0.15-8.49$ & 0.52 \\
Q3-5 & 1.78 & 5.93 & $0.52-67.65$ & $0.15^{*}$ \\
Q4-1 & 0.67 & 1.95 & $0.20-18.59$ & 0.56 \\
Q4-3 & 1.68 & 5.35 & $0.85-33.57$ & $0.07 *$ \\
Q4-4 & 1.83 & 6.26 & $0.63-62.63$ & $0.02 *$ \\
Q5 & 1.68 & 5.35 & $0.62-46.10$ & $0.13 *$ \\
Q6 & 1.82 & 6.11 & $0.39-96.09$ & $0.20 *$ \\
Q7 & 3.24 & 25.62 & $0.019-35024.02$ & $0.37 *$ \\
Q8 & 1.49 & 4.43 & $0.79-24.88$ & $0.09 *$ \\
\hline
\end{tabular}

${ }^{*} \mathrm{OR} \geq 2$

integer. The overall risk score for each patient was calculated by summing the scores of each component.

The discrimination ability of the models was assessed by the area under the receiver operating characteristic (ROC) curve. Discriminatory power is the ability to identify cervical myelopathy. An area of 1.00 under the ROC curve indicates perfect discrimination, whereas an area of 0.50 indicates complete absence of discrimination. The calibration was also evaluated by comparing the prevalence of cervical myelopathy in the score. To examine the performance of the questionnaire, the sensitivity, specificity, positive likelihood ratio, and negative likelihood ratio were calculated. This questionnaire needed a high sensitivity and a low negative likelihood ratio $(<0.1)$ for screening. The positivity criterion for the presence of cervical myelopathy was defined as the point with sufficiently high sensitivity for screening. All statistical analyses were performed using the SPSS software program (version 11.0.1) running on Microsoft Windows Vista (Microsoft, Redmond, WA, USA).

\section{Table 5 Scoring}

\begin{tabular}{lllllc}
\hline Item & $\begin{array}{l}\boldsymbol{\beta} \text { - } \\
\text { coefficient }\end{array}$ & $\begin{array}{l}\text { Adjusted } \\
\text { OR }\end{array}$ & $\mathbf{9 5 \%} \mathbf{C l}$ & $\begin{array}{l}\boldsymbol{p} \\
\text { value }\end{array}$ & $\begin{array}{c}\text { Assigned } \\
\text { score }\end{array}$ \\
\hline Q3-3 & 2.06 & 7.88 & $1.20-51.59$ & 0.031 & 2 \\
Q3-5 & 1.07 & 2.92 & $0.40-21.16$ & 0.29 & 1 \\
Q4-3 & 1.41 & 4.09 & $0.89-18.77$ & 0.07 & 1 \\
Q4-4 & 1.30 & 3.68 & $0.61-22.28$ & 0.16 & 1 \\
Q5 & 1.87 & 6.50 & $0.95-44.31$ & 0.056 & 2 \\
Q6 & 1.54 & 4.65 & $0.35-61.71$ & 0.24 & 2 \\
Q7 & 2.78 & 16.14 & $0.087-$ & 0.30 & 3 \\
& & & 3003.79 & & \\
Q8 & 1.31 & 3.70 & $0.82-16.63$ & 0.019 & 1 \\
\hline
\end{tabular}




\section{Results}

\section{Univariate analysis}

The 20 items were subjected to univariate analysis and the OR was calculated for each item (Table 3). Thirteen items had an OR $\geq 2$ and $\mathrm{p}<0.05:$ Q1-3, Q2-1, Q3-2, Q3-3, Q3-4, Q3-5, Q4-1, Q4-3, Q4-4, Q5, Q6, Q7, and Q8. Most items representing lower leg function, bladder function, and subjective symptoms were included. In contrast, upper extremity items were not significant, which suggested that patients in both groups had upper extremity disorders. Thus, the 13 items with an $\mathrm{OR} \geq 2$ and $\mathrm{p}<0.05$ were chosen for the next step.

\section{Multiple logistic regression analysis}

On multiple logistic regression analysis using the 13 items (Table 4), the $\beta$-coefficients, adjusted ORs, 95\%CI, and $\mathrm{p}$ values were calculated. Eight of the thirteen items had an adjusted OR $\geq 2$ : Q3-3, Q3-4, Q4-3, Q4-4, Q5, Q6, Q7, and Q8. Multiple logistic regression analysis was again performed with these eight items. For the final model, the Hosmer-Lemeshow statistic showed $\mathrm{p}=$ 0.805 , indicating good calibration.

\section{Assignment of scores}

According to the calculated $\beta$-coefficients, score values were defined for the eight items. An integer score derived from the $\beta$-coefficients was assigned to the identified items (Table 5). For each patient, all applicable score values were summed up to attain a total score for the patient. The sum of the risk scores for each patient ranged from 0 to 13 (Figure 1). Finally, a self-administered questionnaire was developed (Table 6). The area under the ROC curve was 0.86 ; thus, the model had good discriminatory power (Figure 2).

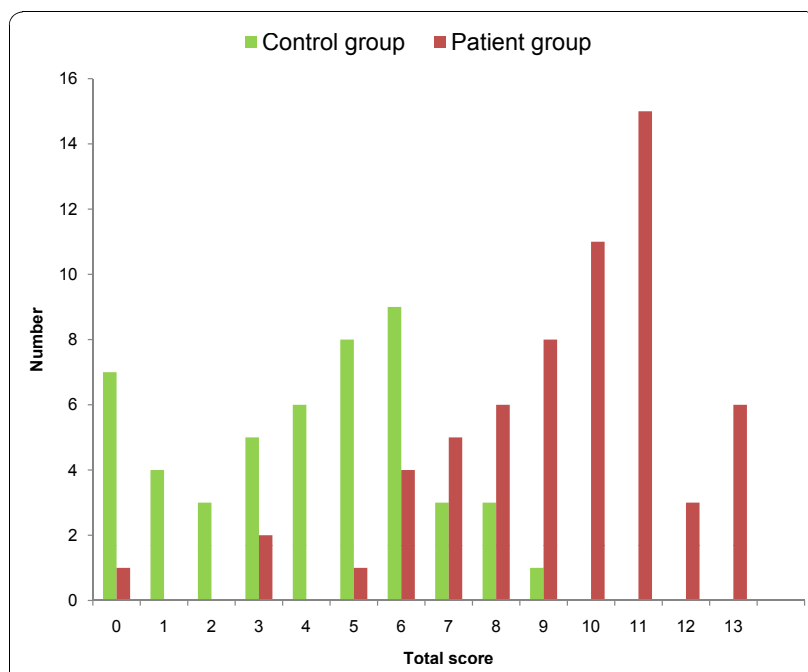

Figure 1 Histogram showing the distribution of the total scores in the two groups.
Table 6 Self-administered questionnaire

\begin{tabular}{lc}
\hline & $\begin{array}{c}\text { Assigned } \\
\text { score }\end{array}$ \\
\hline $\begin{array}{l}\text { Do you have difficulty climbing the stairs to one floor } \\
\text { above? }\end{array}$ & 2 \\
$\begin{array}{l}\text { Do you have difficulty walking for } 15 \text { minutes? } \\
\text { Do you have a feeling of residual urine in your bladder } \\
\text { after voiding? }\end{array}$ & 1 \\
Can you initiate (start) your urine stream immediately & 1 \\
$\begin{array}{l}\text { when you want to void? } \\
\begin{array}{l}\text { Do you have neck pain, shoulder pain, and neck } \\
\text { stiffness? }\end{array}\end{array}$ \\
$\begin{array}{l}\text { Do you have chest tightness? } \\
\text { Do you have pain or numbness in the upper extremity? }\end{array}$ & 2 \\
Do you have pain or numbness from chest to forefoot? & 3 \\
\hline
\end{tabular}

Total score cut-off point: $\geq 6$

Sensitivity: $93.5 \%$

Specificity: $67.3 \%$

Positive likelihood ratio: 2.96

Negative likelihood ratio: 0.096

\section{Setting of the cut-off point}

The positivity cut-off point was defined as 6 , because the sum of the sensitivities was sufficient for screening. Given that the positivity criterion for the score was greater than 6 , this questionnaire had a sensitivity of $93.5 \%$, a specificity of $67.3 \%$, a positive likelihood ratio of 2.96, and a negative likelihood of 0.096 .

\section{Discussion}

Patients with cervical myelopathy have various symptoms, such as numbness, pain, hypoesthesia and

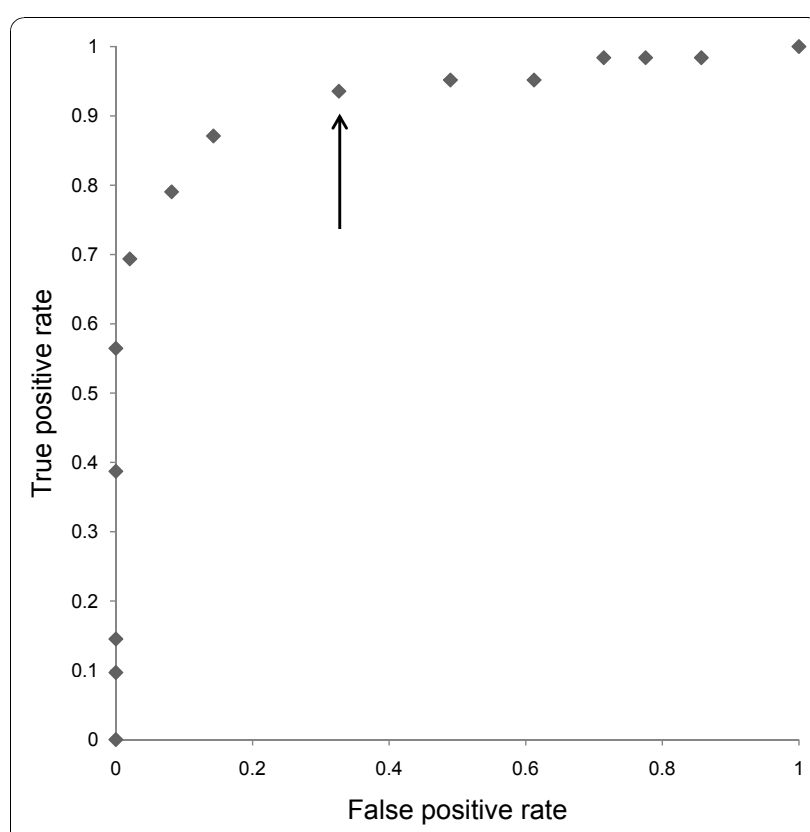

Figure 2 Receiver operating characteristic (ROC) curves. The arrow shows the cut-off point assigned to 6 . 
weakness of the extremities, pain and stiffness of the neck, manual clumsiness, walking disturbance, and urinary disturbance [2-5]. Because upper extremity symptoms may be caused by other diseases including cervical myelopathy, entrapment neuropathy, and diabetes mellitus, it is difficult to distinguish between cervical myelopathy and other diseases. The clinical findings of cervical myelopathy did not have a high sensitivity, so an experienced physician was required to make the diagnosis. Cervical myelopathy is diagnosed based on the symptoms, neurological findings, and magnetic resonance images. However, there is no gold standard for cervical myelopathy. It is reported that $20 \%$ of patients with cervical myelopathy have no myelopathic signs, including Hoffmann's sign, an inverted brachioradialis reflex, clonus, and Babinski's sign [11]. Therefore, a method to easily screen for cervical myelopathy in primary care clinics is needed.

In this study, a self-administered questionnaire including eight items to screen for cervical myelopathy was developed. In the present study, the item pool was chosen from JOACMEQ, a self-administered questionnaire used as an outcome measurement for patients with cervical myelopathy, that was developed using epidemiological approaches and has been shown to have validity, reliability, and responsiveness [6-9]. JOACMEQ consists of four subgroups: function of the cervical spine, upper extremities, lower extremities, and bladder. In the questionnaire developed in this study, items for lower leg function and urination disorder were included. These facts suggests that long tract signs are important for making the diagnosis of cervical myelopathy, which is in agreement with clinical practice.

When the cut-off point for the total score was set at 6 , the sensitivity was $93.5 \%$ and the specificity was $67.3 \%$. These values are sufficiently high for screening. The positive likelihood ratio for this questionnaire was 2.96 . This value means that this questionnaire is not useful for making a definitive diagnosis of cervical myelopathy. The negative likelihood was 0.096 , which means that this questionnaire is useful to rule out the other diseases. Therefore, these results suggest that the questionnaire developed in this study is useful for cervical myelopathy screening.

The fact that the patient group comprised only surgical cases is one of the limitations of this study. To develop the questionnaire, only surgical cases were included in the patient group because they had a confirmed diagnosis of cervical myelopathy. Because this questionnaire is intended to be used to screen for cervical myelopathy in the primary care setting, however, a validation study using a larger group that includes mild, non-surgical cases of cervical myelopathy is required to test the questionnaire's validity and reliability. Another limitation of this study is that the control group consisted mostly of patients with peripheral entrapment neuropathy who underwent surgery; therefore, diseases of various severities should be evaluated. Despite these limitations, this new self-administered questionnaire is effective and easy to use in clinical practice. This questionnaire has only eight items that fit on 1 A4-sized page and patients can complete the questionnaire in about $5 \mathrm{~min}$. We expect that the use of this questionnaire in primary care would improve the accuracy of cervical myelopathy screening. Further studies are needed to investigate the accuracy of this questionnaire in patients with cervical myelopathy of various degrees of severity.

\section{Conclusion}

We developed a simple self-administered questionnaire to screen for cervical myelopathy in outpatients.

\section{Acknowledgements}

I would like to thank Dr. Maruya and Dr takahashi who helped this study in the outpatient.

\section{Authors' contributions}

HK, SK conceived the study and participated in the study design. HK performed the statistical analysis. HK drafted the initial manuscript for journal submission. All authors coordinated data collection. All authors read and approved the final manuscript.

\section{Competing interests}

The authors declare that they have no competing interests.

Received: 24 June 2010 Accepted: 22 November 2010 Published: 22 November 2010

\section{References}

1. Bohlman HH, Emery SE: The pathophysiolosy of cervical spondylosis and myelopathy. Spine 1988, 13:843-845.

2. McCormack BM, Weinstein PR: Cervical spondylosis: An update. West J Med 1996, 165:43-51

3. Young WF: Cervical spondylotic myelopathy: A common cause of spinal cord dysfunction in older persons. Am Fam Physician 2000, 62:1064-1073.

4. Emery SE: Cervical spondylotic myelopathy; Diagnosis and treatment. J Am Acad Orthop Surg 2001, 9:376-388.

5. Clarke E, Robinson PK: Cervical myelopathy: a complication of cervical spondylosis. Brain 1956, 79:483-510.

6. Fukui M, Chiba K, Kawakami M, Kikuchi S, Konno S, Miyamoto M, Seichi A, Shimamura T, Shirado O, Taguchi T, Takahashi K, Takeshita K, Tani T,

Toyama Y, Wada E, Yonenobu K, Tanaka T, Hirota Y: Subcommittee on Low Back Pain and Cervical Myelopathy Evaluation of the Clinical Outcome Committee of the Japanese Orthopaedic Association. An outcome measure for patients with cervical myelopathy: Japanese Orthopaedic Association Cervical Myelopathy Evaluation Questionnaire (JOACMEQ): Part 1. J Orthop Sci 2007, 12:227-240.

7. Fukui M, Chiba K, Kawakami M, Kikuchi S, Konno S, Miyamoto M, Seichi A, Shimamura T, Shirado O, Taguchi T, Takahashi K, Takeshita K, Tani T, Toyama Y, Wada E, Yonenobu K, Tanaka T, Hirota Y: Subcommittee on Low Back Pain and Cervical Myelopathy Evaluation of the Clinical Outcome Committee of the Japanese Orthopaedic Association. Japanese Orthopaedic Association Cervical Myelopathy Evaluation Questionnaire (JOACMEQ): Part 2. Endorsement of the alternative. J Orthop Sci 2007, 12:241-248.

8. Fukui M, Chiba K, Kawakami M, Kikuchi S, Konno S, Miyamoto M, Seichi A, Shimamura T, Shirado O, Taguchi T, Takahashi K, Takeshita K, Tani T, Toyama Y, Yonenobu K, Wada E, Tanaka T, Hirota Y: Japanese Orthopaedic 
Association Cervical Myelopathy Evaluation Questionnaire: Part 3.

Determination of reliability. J Orthop Sci 2007, 12:321-326.

9. Fukui M, Chiba K, Kawakami M, Kikuchi S, Konno S, Miyamoto M, Seichi A, Shimamura T, Shirado O, Taguchi T, Takahashi K, Takeshita K, Tani T,

Toyama Y, Yonenobu K, Wada E, Tanaka T, Hirota Y: Japanese Orthopaedic Association Cervical Myelopathy Evaluation Questionnaire (JOACMEQ):

Part 4. Establishment of equations for severity scores. J Orthop Sci 2008, 13:25-31.

10. Nikaido T, Kikuchi S, Yabuki S, Otani K, Konno S: Surgical Treatment Assessment Using the Japanese Orthopedic Association Cervical Myelopathy Evaluation Questionnaire in Patients With Cervical Myelopathy. Spine 2009, 23:2568-2572.

11. Rhee JM, Heflin JA, Hamasaki T, Freedman B: Prevalence of Physical Signs in cervical Myelopathy. Spine 2009, 34:890-895.

\section{Pre-publication history}

The pre-publication history for this paper can be accessed here: http://www.biomedcentral.com/1471-2474/11/268/prepub

Cite this article as: Kobayashi et al.: Development of a self-administered questionnaire to screen patients for cervical myelopathy. BMC

Musculoskeletal Disorders 2010 11:268.

\section{Submit your next manuscript to BioMed Central} and take full advantage of:

- Convenient online submission

- Thorough peer review

- No space constraints or color figure charges

- Immediate publication on acceptance

- Inclusion in PubMed, CAS, Scopus and Google Scholar

- Research which is freely available for redistribution

Submit your manuscript at www.biomedcentral.com/submit
Ciomed Central 